\title{
The Rarest Flamingo
}

\section{Tony Morrison}

The James's or lesser Andean flamingo Phoenicoparrus jamesi is undoubtedly the world's rarest flamingo. Very little is known of its habits, status or distribution, mainly because of the extreme isolation of its usual haunts in the high semi-desert wilderness region of the southern Bolivian Andes. The birds have never been recorded below 9000 feet.

Discovered in the 1880 s by an expedition sponsored by a British businessman, $\mathrm{H}$. Berkeley James, which returned with several museum specimens, James's flamingo was not recorded again (because no field workers visited the region) until 1956, when A. W. Johnson (author of Birds of Chile), with four companions, rediscovered it nesting on the Laguna Colorada, a spectacular lake set among the blackened cones of extinct volcanoes, at 14,000 feet in the southern highlands of Bolivia. The water is brick red, coloured by minute algae, and around the shoreline immense deposits of white salt glisten in the cold Andean sunlight. Other ornithologists followed Johnson's trail, some reporting a few hundred flamingos and some only a handful, often as few as ten; the largest number was an estimated 10,000 in November 1965. The erratic numbers are not surprising in view of the unusual breeding cycles of flamingos, but there remains the major question of where the birds go when they are not on the Laguna Colorada.

It may be that a new climatic factor is influencing the flamingos' distribution. Geological evidence shows that the entire region of the Atacama and high Bolivian desert has been subjected over thousands of years to successive periods of desiccation. The last major change was about ten thousand years ago, but there are indications that another, drier period started at some time within the last two hundred years and is now affecting the Laguna Colorada and nearby lakes. Many of the high mountains have been devoid of snow since 1964 and there have been seasons of intense cold. Freezing cold days and nights are not unusual at the Laguna Colorada, and a pre-dawn temperature of $15^{\circ} \mathrm{C}$. is customary in June or July. But in 1967 the temperature in these months was often $-25^{\circ} \mathrm{C}$; one expert with fifteen years' experience in south Bolivia considered that it was the coldest winter he had known. During the mid-winter months James's flamingos were found over a great area of the south-central Andes; some were reported from the Las Salinas lake above the city of Arequipa in Peru, 750 miles north of the Laguna Colorada.

Since the very cold year, the flamingos seem to have remained widely dispersed, and unfortunately they are now found in more densely inhabited areas. A particular threat is the tribe of Chipaya Indians in the Bolivian province of Carangas, who hunt flamingos, using traps or a bolas; they catch all three Andean species, regardless of the rarity of jamesi, using the feathers for trade and the oil for medicine. Other, smaller tribal groups also rely on the high Andean avifauna for 


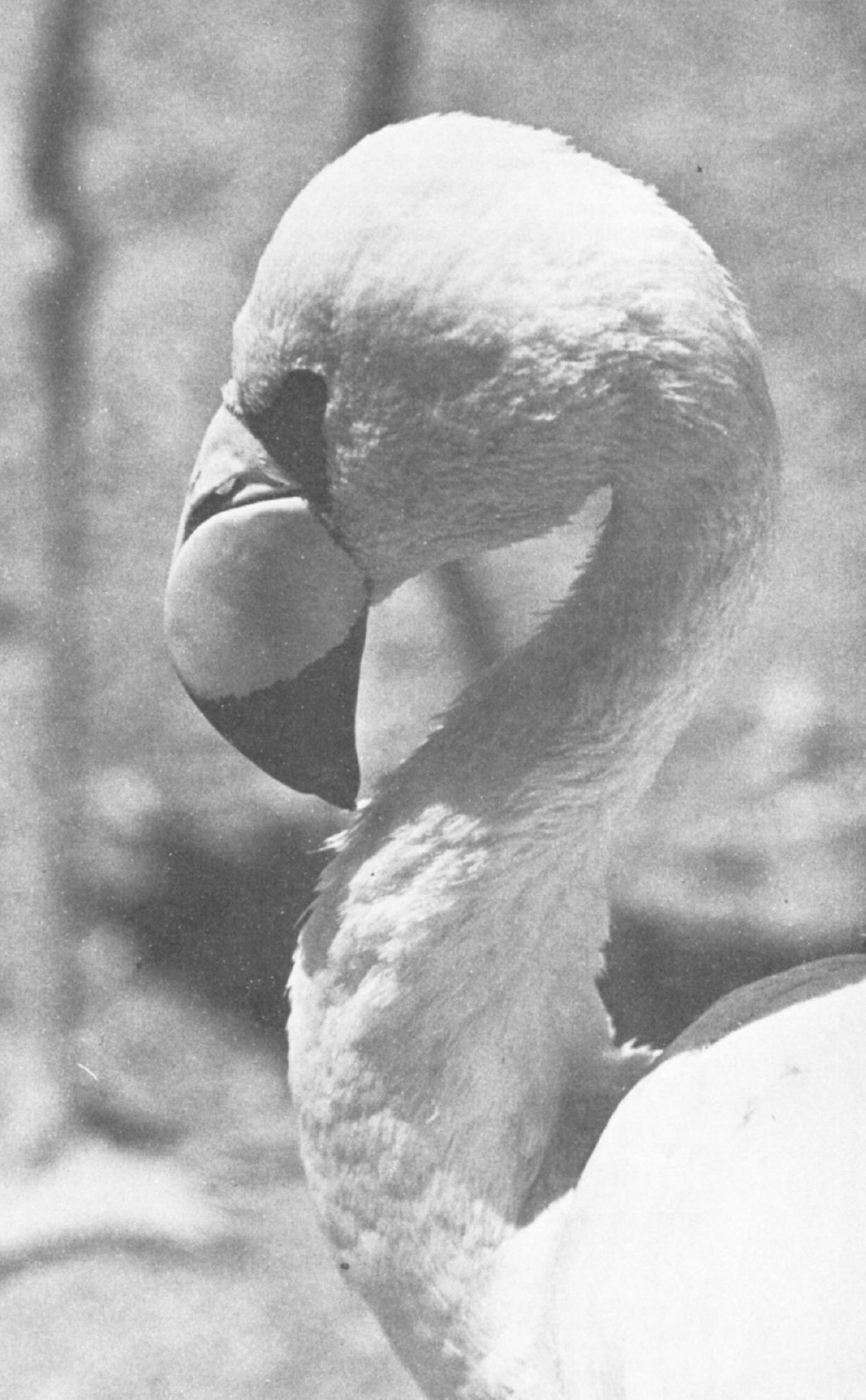


food, and all the Indians of the region collect eggs during the nesting season. In 196725,000 eggs were taken from one area and sold in markets in some major Bolivian towns.

If the climatic change continues to force the rare James's flamingo into new areas, away from the seclusion of the Laguna Colorada and the surrounding semi-explored wilderness, their numbers could be reduced drastically. As the precise status of the species is not known, it is difficult to estimate how tolerant it will be of any change.

\section{Bears and Birds of Prey in Italy}

An interim report on the Abruzzo brown bear survey in Italy (to which the FPS/WWF Revolving Fund contributed) estimates a density of one bear for each five square kilometres in an area (Monti della Difesa, near Pescasseroli) that is believed to provide the optimum bear habitat. In the 360 square $\mathrm{kms}$ under observation there were at least 70 bears, from which it was calculated that, as the bears' range covers at least 520 square $\mathrm{kms}$, the total population may be not less than 100 animals. The report recommends that both refuge and feeding areas be made strict reserves, with an absolute prohibition against cutting plants favoured by bears (66 per cent of their food was found to be herbaceous or fruit); a planting programme of suitable food plants; indemnity payments for damage to domestic stock (which was done in 1965 and 1970 by the Italian WWF, and is now being done by the National Park authorities for the first time in its history), and the reintroduction of herbivores.

The Italian WWF reports that the white-tailed eagle is now extinct in Italy: the last breeding pair has not been seen for three years at its nesting site in Sardinia. The lammergeier is also now believed to be extinct in Italy, and the golden eagle in a very precarious position. Poison baits (often set by hunters) are one of the chief causes of wildlife destruction in Italy, especially to birds of prey, wolves, wild cats and brown bears.

\section{Conservation Filmstrip}

Now that conservation is a word in everyday use, we have the second and more difficult task of explaining what it really means, and a filmstrip such as Dr. D.H. Dalby's Nature Conservation in the British Isles makes a valuable contribution. His photographs are unemotional statements of fact and the lecture notes full and informative, with background information in italics. The filmstrip is divided into three sections with inevitably some overlap between them. The first 'Some major threats' has twelve frames - it seems a pity there was not room for more about such farming techniques as removal of hedges and the effects of coastal development; the second 'How natural are our habitats?' discusses the evolution of our countryside and provokes the question, What is it we are trying to conserve? The third is concerned with conservation measures. Aimed principally at secondary schools, naturalists' trusts and amenity bodies, there is, surprisingly, no mention of Colleges of Education or Teachers' Centres. The education of future generations of adults is fundamental in conservation, but first we must educate our teachers.

The filmstrip, one of a series on the Environment published by Diana Wyllie, is available in the full frame picture size $(35 \mathrm{~mm} \times 24 \mathrm{~mm})$ at $£ 3$ and half frame $(24 \mathrm{~mm} \times 18 \mathrm{~mm})$ at $£ 2.50$, the larger one being easy to cut up and mount as individual slides. 